\title{
Estimation of Stature from Foot Dimensions
}

\author{
Bhaargavi Siripurapu' ${ }^{1}$, Magendran Chandran ${ }^{2}$ \\ ${ }^{1} 2^{\text {nd }}$ Year MBBS, Saveetha Medical College, Thandalam, Chennai-602105, \\ ${ }^{2}$ Professor, Department of Forensic Medicine, Saveetha Medical College, Thandalam, Chennai-602105
}

\begin{abstract}
The purpose of this study is to establish reliability of estimating stature from the foot dimensions in South Indian population. Volunteers aged above 18 years were recruited for the study and measured using standard measuring using standardized measuring equipment. Anthropometric measurements taken include stature,foot length, foot breath, navicular height and malleolar heights. Correlations,regression formula and linear regression equations derived for both male and female showed positive correlation coefficient between stature and foot dimensions. To conclude foot dimensions were correlated with stature and can be a better predictor of stature.
\end{abstract}

Keywords: Stature estimation, footlength, foot breath, navicular height, malleolar height.

\section{Introduction}

Identification of an individual is the mainstay in forensic investigations. This becomes more essential when dismembered body parts are found. Forensic examinations to identify individuals depend on aspects that solely define them such as fingerprints. One of such investigations is stature estimation. Stature is the height of the person in erect posture and this can determine the physical identity of a person. It has a significant aspect in establishing identity of an unknown ${ }^{[1]}$. Stature of an individual belonging to a given combination of age, race, and sex have measurements of different body parts that are proportionate to $\mathrm{it}^{[2]}$. Measurements of long bones are usually used to estimate stature ${ }^{[3]}$. Different parts of the body can also be used for estimation ${ }^{[4][5]}$. As foot dimensions enable determine stature, they also determine age and sex of an individual ${ }^{[6]}$. This forensic assessment of stature helps identify individuals,thereby helping medico-legal and forensic investigations.

\footnotetext{
Corresponding Author:

Bhaargavi Siripurapu

$2^{\text {nd }}$ Year MBBS, Saveetha Medical College,

Thandalam, Chennai-602105

e-mail: bhaargavisiripurapu@gmail.com

Mobile No.: 9493239139
}

\section{Materials and Method}

It is a cross-sectional study consisting of South Indian population. Residents of Chennai irrespective of sex with age above 18 years and those who had given their informed consent were measured for stature,foot length(the maximum distance between the most posteriorly projecting point of the heel (pterion) to the most anteriorly projecting point (acropodion) of the first or second toe, whichever is bigger when the foot is fully stretched),foot breadth(the distance between the lateral and the medial sides at the metatarsal region or at the heel region, whichever is the broadest), navicular height(the distance between the prominent part on the medial side of dorsal foot (navicular bone being situated on the medial side) to the base of foot on the plantar aspect) and malleolar heights (the most superficial prominent point on the malleolus to the base of foot at the heel) using vernier calipers and measuring tape to the nearest centimeter. Since stature is variable among population and sex, regression formulas have been derived fort he population and the data will be tabulated, analyzed and subjected to statistical calculations using SPSS software. 


\section{Results}

Estimation of stature using foot measurements

Table No: 1

\begin{tabular}{|l|c|c|}
\hline Parameter & Male & Female \\
\hline Total Number & 23 & 38 \\
\hline Mean of Height & 167.0261 & 155.9184 \\
\hline S.D of Height & 2.98621 & 5.53846 \\
\hline Mean of FLRT & 24.9261 & 22.7711 \\
\hline S D of FLRT & 1.08302 & 1.02823 \\
\hline Mean of FLLT & 24.8783 & 22.7711 \\
\hline S.D of FLLT & 1.13736 & 1.00079 \\
\hline Mean of FBRT & 9.1652 & 8.0421 \\
\hline S.D of FBRT & .53395 & 0.46361 \\
\hline Mean of FBLT & 9.1174 & 8.0316 \\
\hline S.D of FBLT & .51580 & 0.46155 \\
\hline Mean of NHRT & 5.0870 & 4.3921 \\
\hline S.D of NHRT & .42885 & 0.44381 \\
\hline Mean of NHLT & 5.0913 & 4.3921 \\
\hline S.D of NHLT & .46993 & 0.44684 \\
\hline Mean of LMHRT & 5.7391 & 4.9000 \\
\hline S.D of LMHRT & .73716 & 0.92590 \\
\hline Mean of LMHLT & 5.7522 & 4.8921 \\
\hline S.D of LMHLT & .72980 & 0.91751 \\
\hline Mean of MMHRT & 6.0783 & 5.3921 \\
\hline S.D of Left MMHRT & .75073 & 0.95899 \\
\hline Mean of MMHLT & 6.0826 & 5.4316 \\
\hline S.D of Left MMHLT & .78951 & 0.95920 \\
\hline
\end{tabular}

Table No: 2: Correlation of stature with foot dimensions

\begin{tabular}{|l|c|}
\hline & Correlation \\
\hline FLRT & 0.773 \\
\hline FLLT & 0.754 \\
\hline FBRT & 0.611 \\
\hline FBLT & 0.599 \\
\hline NHRT & 0.820 \\
\hline NHLT & 0.815 \\
\hline LMHRT & 0.645 \\
\hline LMHLT & 0.649 \\
\hline MMHRT & 0.501 \\
\hline MMHLT & 0.490 \\
\hline
\end{tabular}

Table No: 3: Linear Regression equation for Male

\begin{tabular}{|l|c|c|}
\hline & Male & Female \\
\hline FLRT & .188 & 0.649 \\
\hline FLLT & .161 & 0.633 \\
\hline FBRT & .502 & -0.031 \\
\hline FBLT & .477 & -0.046 \\
\hline NHRT & 0.802 & 0.680 \\
\hline NHLT & 0.840 & 0.676 \\
\hline LMHRT & 0.038 & 0.675 \\
\hline LMHLT & 0.026 & 0.670 \\
\hline MMHRT & -0.049 & 0.491 \\
\hline MMHLT & -0.061 & 0.507 \\
\hline
\end{tabular}

\section{Regression equation SEE}

$\mathrm{S}=154.107+0.518$ FLRT3.00200

$\mathrm{S}=156.498+0.423$ FLLT3.01653

$\mathrm{S}=141.278+2.809$ FBRT2.64288

$S=141.856+2.761$ FBLT2.68656

$\mathrm{S}=138.627+5.583 \mathrm{NHRT} 1.82685$

$\mathrm{S}=139.857+5.336 \mathrm{NHLT} 1.65959$

$S=166.149+0.153$ LMHRT3.05431

$\mathrm{S}=166.418+0.106 \mathrm{LMHLT} 3.05547$

$\mathrm{S}=168.206-0.194 \mathrm{MMHRT} 3.05284$

$\mathrm{S}=168.441-0.233 \mathrm{MMHLT} 3.05070$

\section{Linear Regression equation for Female}

\section{Regression equation SEE}

$S=76.262+3.498$ FLRT4.26964

$\mathrm{S}=76.105+3.505$ FLLT 4.34513

$S=158.921-0.373$ FBRT5.61211

$S=160.353-0.552 F B L T 5.60891$

$\mathrm{S}=118.633+8.489$ NHRT 4.11560

$\mathrm{S}=119.102+8.382$ NHLT4.13615

$\mathrm{S}=136.135+4.038$ LMHRT4.14284

$\mathrm{S}=136.128+4.045 \mathrm{LMHLT} 4.16737$

$\mathrm{S}=140.616+2.838 \mathrm{MMHRT} 4.89023$

$\mathrm{S}=140.021+2.927 \mathrm{MMHLT} 4.84001$ 


\begin{tabular}{|c|c|c|c|c|c|c|c|c|c|c|c|}
\hline \multicolumn{12}{|c|}{ Correlations } \\
\hline & Height & FLRT & FLLT & FBRT & FBLT & NHRT & NHLT & LMHRT & LMHLT & MMHRT & MMHLT \\
\hline Height & 1 & $.773^{* *}$ & $.754^{* *}$ & $.611^{* *}$ & $.599^{* *}$ & $.820^{* *}$ & $.815^{* *}$ & $.645^{* *}$ & $.649^{* *}$ & $.501^{* *}$ & $.490^{* *}$ \\
\hline FLRT & & 1 & $.992^{* *}$ & $.649^{* *}$ & $.655^{* *}$ & $.655^{* *}$ & $.647^{* *}$ & $.497^{* *}$ & $.507^{* *}$ & $.422^{* * *}$ & $.426^{* *}$ \\
\hline FLLT & & & 1 & $.639^{* *}$ & $.649^{* *}$ & $.641^{* *}$ & $.627^{* *}$ & $.483^{* *}$ & $.493^{* *}$ & $.416^{* *}$ & $.423^{* *}$ \\
\hline FBRT & & & & 1 & $.993^{* *}$ & $.543^{* *}$ & $.559^{* *}$ & $.265^{*}$ & $.284^{*}$ & $.264^{*}$ & .247 \\
\hline FBLT & & & & & 1 & $.531^{* *}$ & $.547^{* *}$ & $.265^{*}$ & $.282^{*}$ & $.278^{*}$ & $.261^{*}$ \\
\hline NHRT & & & & & & 1 & $.985^{* *}$ & $.505^{* *}$ & $.516^{* *}$ & $.326^{*}$ & $.304^{*}$ \\
\hline NHLT & & & & & & & 1 & $.495^{* *}$ & $.505^{* *}$ & $.316^{*}$ & $.292^{*}$ \\
\hline LMHRT & & & & & & & & 1 & $.998^{* *}$ & $.929^{* *}$ & $.923^{* *}$ \\
\hline LMHLT & & & & & & & & & 1 & $.927^{* *}$ & $.921^{* *}$ \\
\hline MMHRT & & & & & & & & & & 1 & $.993^{* *}$ \\
\hline MMHLT & & & & & & & & & & & 1 \\
\hline
\end{tabular}

Regression equation, Regression equation \pm SEE, $S=81.616+2.711 \mathrm{FLRT}-1.342 \mathrm{FLLT}+6.835 \mathrm{FBRT}-5.306 \mathrm{FBLT}+5.690 \mathrm{NHRT}-$ 0.429NHLT+14.463LMHRT-11.470LMHLT- 2.436MMHRT+1.197MMHLT \pm 3.1985

\section{Discussion}

In forensic investigations difficulties are being experienced in identification of bodies dismembered in mass destruction. So as to minimize these difficulties many method are developed and are being developed. One such investigation is stature estimation which helps in identifying individuals. Stature estimation can be done with different parts of the body. This assessment is of great importance in medico-legal and forensic examinations. The present study is to estimate stature from foot measurements and to analyze relationship between foot dimensions and stature.

It is a cross-sectional study in South Indian population. Residents of Chennai irrespective of sex with age above 18 years and informed consent given are measured for stature, foot length, foot breath,navicular height and malleolar heights. Those with deformities and below 18 years of age were excluded from the study.

Table 1 shows the mean and standard deviation of various measurements of both right and left foots in males and females,along with height. In the present study $62.30 \%$ are of females and $37.70 \%$ are males. The mean height of males is 167.0261 and females is 155.9184 .

The mean height is more in males than females though female to male ration is low. The mean of other foot dimensions also show more for males than females.
Table 2 shows correlation of stature with foot dimensions of both right and left.Also shows correlation of various parameters in males and females.

Almost all correlation coefficients show positive values indicating a relation between various parameters and stature. Foot breadth in females and malleolar height in males show negative correlation indicates less relation between stature and these two parameters.

Correlation coefficient of foot length in females is 0.649 and males is .188 says that foot length is more correlated to stature in females than males.

Correlation coefficient foot breath in males is .502 and -0.046 in females indicates that foot breath is more correlated to stature in males than females. Foot breadth in females have negative correlation with stature.

Correlation coefficient of navicular height in males is 0.840 and 0.680 in females says that navicular height is more correlated to stature in males than females.

Correlation coefficient lateral malleolar height in females is 0.675 in females and 0.038 in males indicates that lateral malleolar height is more correlated to stature in females than males.

Correlation coefficient of medial malleolar height in females is 0.507 and -0.061 in males says medial malleolar height is more correlated to stature in females than males. 
Foot breath in females and medial malleolar height in males are negatively correlated to stature that is increase in one variable is associated with a decrease in the other variable.

Correlation of the parameters with stature show positive values in total indicating a relation between stature and foot dimensions.

Table 3 shows linear regression equations for males and females.

The SEE help predict the deviation of estimated stature from the actual stature. A low value indicates a greater reliability in the estimated stature.

The SEE ranges from 1.65959 to 3.05547 in males. Navicular height exhibits a lower value and gives better reliability in prediction of stature.

The SEE ranges from 4.11560 to 5.61211 in females. Navicular height exhibits a lower value and gives better reliability in prediction of stature.

In this study navicular height in both males and females presented a strong relationship with stature and more reliable in estimation of stature.

The results of the present study show that dimensions of foot show statistically significant positive correlation with stature of an individual. In this study males showed higher mean values in all the parameters studied than among females with statistically significant difference. Sexual dimorphism was noted for the foot dimensions recorded. The foot dimensions are relatively smaller in females than males. No significant difference was found in either right or left side measurements.

\section{Conclusion}

The present study established a definite relationship between stature and foot dimensions. The above findings suggest that foot dimensions can be predictors of stature. However, the results of this study is different from the studies previously conducted. Thus cannot be used to make any firm conclusions. It is important to note that results differ with races and geographical distribution.

Ethical Clearance: Taken from Institutional ethical committee.

\section{Source of Funding: Self}

\section{Conflict of Interest: Nil}

\section{References}

1. Kanchan T, Menezes RG, Moudgil R, Kaur R, Kotian MS, Garg RK. Stature estimation from foot length using universal regression formula in a North Indian population. Journal of forensic sciences. 2010 Jan;55(1):163-6.

2. Krishan K. Estimation of stature from cephalofacial anthropometry in north Indian population. Forensic Science International. 2008 Oct 25;181(13):52-e1.

3. Kamal, Renu; Yadav, Praveen Kumar. Estimation of stature from different anthropometric measurements in Kori population of North India. Egyptian Journal of Forensic Sciences. 2016 Dec; 6(4):468-477.

4. Hussein, Sheik Shakeer S; Balachandran, Ajay. Determination of Stature from the Length of Middle Finger - An Autopsy Study. Journal of Evolution of Medical and Dental Sciences. 2017 Aug;6(70):5009-12.

5. Hussein, Sheik Shakeer S; Balachandran, Ajay. The Relationship Between Foot Index and Stature in Kerala Population - A Descriptive Study. Journal of Evolution of Medical and Dental Sciences. 2017 Sept;6(73):5221-24.

6. Kanchan T, Menezes RG, Moudgil R, Kaur R, Kotian MS, Garg RK. Stature estimation from foot dimensions. Forensic Science International. 2008 Aug 6;179(2-3):241-e1. 